\title{
Effectiveness of minimal intervention by general practitioners with their smoking patients: a randomised, controlled trial in France
}

\author{
Karen Slama, Serge Karsenty, Albert Hirsch
}

\begin{abstract}
Objective - To investigate the impact of a very minimal smoking cessation intervention in general practice in 1991.

Design - A randomised, controlled clinical trial.

Setting-The practices of 372 general practitioners in the region ProvenceAlpes-Côte d'Azur in France.

Subjects - Smoking patients seen in office consultations over a four-week period.

Intervention-Doctors asked their patients if they smoked, and gave brochures to those smokers who wanted to stop. Controls were not questioned about their smoking.

Main outcome measures - Self-reported initial smoking cessation and sustained abstinence for one year following the trial.
\end{abstract}

Results - A total of 5560 smokers received the intervention. A random sample of 2199 smokers who gave their consent to be re-contacted was compared with 929 smokers identified among a random sample of controls who consented to be re-contacted. Cessation at one month was significantly higher among smokers receiving the intervention $(6.8 \% v 4.1 \%$; difference $=2.7$ percentage points, $95 \%$ confidence interval $(C I)=1.05$ to $4.35 ; \chi^{2}$ $=8.379, \mathrm{df}=1, \mathrm{p}<0.005)$. For those who stopped at one month, differences in abstinence remained at 12-month follow up: $1.9 \%$ in the experimental group had remained abstinent without relapsing since the one-month follow up, compared with $0.5 \%$ among controls (difference = 1.4 percentage points, $95 \% \mathrm{CI}=0.67$ to $\left.2.13 ; \chi^{2}=8.304, \mathrm{df}=1, \mathrm{p}<0.005\right)$.

Conclusion-General practitioners may have increased cessation among their smoking patients in the month following their consultation by up to $60 \%$ over natural cessation rates by simply asking about smoking and providing material for smokers who wished to stop. Smokers receiving the intervention were more likely to remain abstinent; at 12 months, the rates for sustained abstinence were four times greater than those among controls.

(Tobacco Control 1995; 4: 162-169)

Keywords: smoking cessation; general practice; France

\section{Introduction}

General practitioners (GPs) have the potential to play a major role in tobacco control by motivating smokers to stop smoking, and helping them to do so if necessary. ${ }^{1}$ Many practitioners, however, appear to be reticent to become involved in smoking cessation efforts of a routine nature. ${ }^{2}$

Most doctors offer advice or guidance to some smoking patients, but often omit giving advice to others. This approach seems to be inefficient, as studies have shown that doctors are more likely to offer advice to the smokers least likely to quit without extensive help ${ }^{3,4}$ for example, smokers who continue to smoke despite smoking-related symptoms or illnesses, heavily dependent smokers and pregnant women smokers who have not quit on their own. In addition, high relapse rates among patients who attempt to stop offer little reinforcement for the doctor. Both of these factors may lead doctors to believe that brief interventions are ineffective, or that they personally are unable to provide effective counselling. ${ }^{5}$

Structural issues such as time constraints or perceived lack of compatibility with practice procedure may also impede routine implementation of advice or counselling about smoking cessation. Doctors may feel unable to deal with the "Pandora's box" of talking about smoking and cessation, its being considered too timeconsuming for a normal consultation. In addition, particularly in Latin countries, doctors are often loath to intervene in patients' lifestyle choices, especially when not asked to do so, as these choices are not considered to be an aspect of medical treatment.

To counter these impediments to action, it could be useful to investigate the effectiveness on initial and sustained cessation of a very brief procedure that does not challenge the patient, makes no demands on the persuasive abilities of the general practitioner, and which can be implemented without delaying normal consultation procedures. If such an intervention increased long-term cessation, it could serve as a basic procedure for all smoking patients, with additional counselling or treatment to be added when possible.

Smoking cessation intervention trials in general practice have usually shown higher quit rates for intervention patients than for controls. ${ }^{6,7,8}$ Differences between brief intervention groups and controls, however, may not demonstrate statistical significance due to

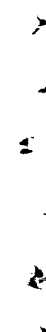

$$
\geqslant
$$

$\geqslant$

4

Service de
Pneumologie,
Saint-Louis, Pa
France
K Slama
A Hirsch
INSERM U357,

Kremlin-Bicêtre,

France 10, France 
insufficient sample size. ${ }^{9,10}$ This report presents the results of a randomised trial of a smoking cessation intervention involving the patients of 372 general practitioners in the south of France. Because of the large number of smokers included, it was possible to test the effect of minimal involvement on the part of the general practitioner. Studies indicate greater cessation if the GP spends more rather than less time in counselling smokers ${ }^{11}$ but the object of this study is to identify the minimum action possible that could significantly reduce smoking prevalence. Thereafter, doctors could be asked to implement this minimum routinely, and be encouraged to add other elements according to their own availability and competence, or the patient's needs.

\section{Methods}

GENERAL PRACTITIONERS

Survey interviewers recruited GPs into the trial by telephone in three departments in the south of France. Participating doctors were then again contacted by phone before the intervention to reinforce their understanding of the protocol, and then weekly to encourage continued participation. To increase the quality of the evaluation, telephone contact with the participating GPs was provided by 50 general practitioner-coordinators recruited and trained in the protocol who did not themselves participate in the trial.

\section{SUBJECTS}

Participating GPs were asked to enroll all patients 15 years of age or older who were seen in consultations during the period 13 May to 8 June 1991. Accompanying persons were not enrolled, nor were patients seen in home visits.

Participating GPs received written instructions, a one-sheet prompt of the protocol, and intervention materials: colour-coded patient randomisation sheets which indicated control or intervention conditions, 50 booklets (cessation guides) to give to interested smokers in the intervention condition, and stamped, addressed envelopes for weekly return of the patient randomisation sheets.

During the trial period, at the end of each consultation, the doctor randomised each patient according to the uppermost sheet of the patient information sheets. The sheets were gummed together at the top in a block to encourage the GPs to use them in the order provided and thus maintain the randomisation procedure. Yellow sheets indicated the intervention condition, white the control condition in the proportion of $2: 1$. The unequal proportions were felt to be necessary so that doctors would feel that they were frequently intervening.
"Are you currently a smoker?" Those who answered "no" were excluded. Smokers were then asked: "Do you want to stop smoking?" Those who answered "yes" were given a cessation guide published by the French National Committee for Health Education, "fe tabastoppe". This brochure gave an overview of psychological and physical dependence, self-tests about dependence and motivation, information concerning low-tar cigarettes, cold-turkey $v$ progressive stopping, the physical effects of cessation, a description of treatments that exist, and a description of one smoker's successful quitting experience.

The contents of the brochure are not considered a necessary part of the intervention for the patients, but the brochure itself was considered necessary for the doctors as a legitimate response to the smokers' declaration of a desire to quit. Doctors then asked all smokers, regardless of their desire to stop or not stop smoking, the question: "In the course of a large survey, the Regional Health $\mathrm{Ob}$ servatory would like to contact patients having seen their doctor this month. Would you be willing for me to give them your name and telephone number for a very brief questionnaire?" It was necessary to ask for consent in this way because of French legislation concerning experimental trials.

Control patients were not asked about their smoking status, as this in essence was the intervention being tested. Like the smokers in the intervention group, controls were asked the same question concerning consent to be interviewed by the Regional Health Observatory. The smoking status of the control patients would be determined only one month later, at the time of the one-month follow-up survey (figure).

Whether or not the patient gave consent for follow up, each patient's randomisation sheet was completed, detached from the block, and inserted into a stamped, addressed envelope to be mailed at the end of each week.

The intervention condition consisted of two questions and the provision of a cessation guide to interested smokers. All intervention patients seen in the trial period were asked:
MEASURES

All measures outside the consultation were made by professional interviewers contracted $N$ by the study organisers. They were totally uninvolved in tobacco-use research. Smokers in the control group were identified in a telephone interview one month after the trial. All control group subjects contacted were asked: "Have you ever been a smoker?"'Those $\stackrel{\mathscr{\Phi}}{\rightarrow}$ individuals who indicated having been a $T$ smoker within the previous two months were interviewed further; those who had quit before seeing their doctor were excluded, and the $\mathbb{Q}$ control sample then consisted of patients who $\overline{2}$ had all been smokers at the time of their visit 8 with the general practitioner. Self-defined smoking status in the intervention group was known at baseline due to the intervention. All subjects' demographic and smoking history data were gathered at the time of the onemonth follow up. Long-term smoking status data were obtained by telephone 12 months after the initial consultation. Follow up at 12 
months gave the opportunity to ask about smoking behaviour over the 11 months after the initial follow up.

The variables investigated were sex, age, level of education, employment, profession, family situation, age starting smoking, previous tobacco consumption, prior cessation, difficulty in stopping, motive for stopping, and also one-year follow-up measures of education, employment, profession, and family situation. Statistical values were computed for two-tailed $\chi^{2}$ analysis, but in some cases one-tailed results are included, as results are expected in one direction only.

\section{Results}

GENERAL PRACTITIONERS

A random sample of 749 GPs $(14.6 \%$ ) from a list of all currently practicing GPs in three regional districts $(n=5119)$ were asked if they would participate in a brief smoking cessation intervention with their patients. Of a total of 617 GPs who initially agreed to take part $(82.4 \%$ of those contacted), 372 general practitioners $(49.7 \%$ of doctors initially contacted) provided evidence of participation by returning patient randomisation sheets. Data

Intervention phase

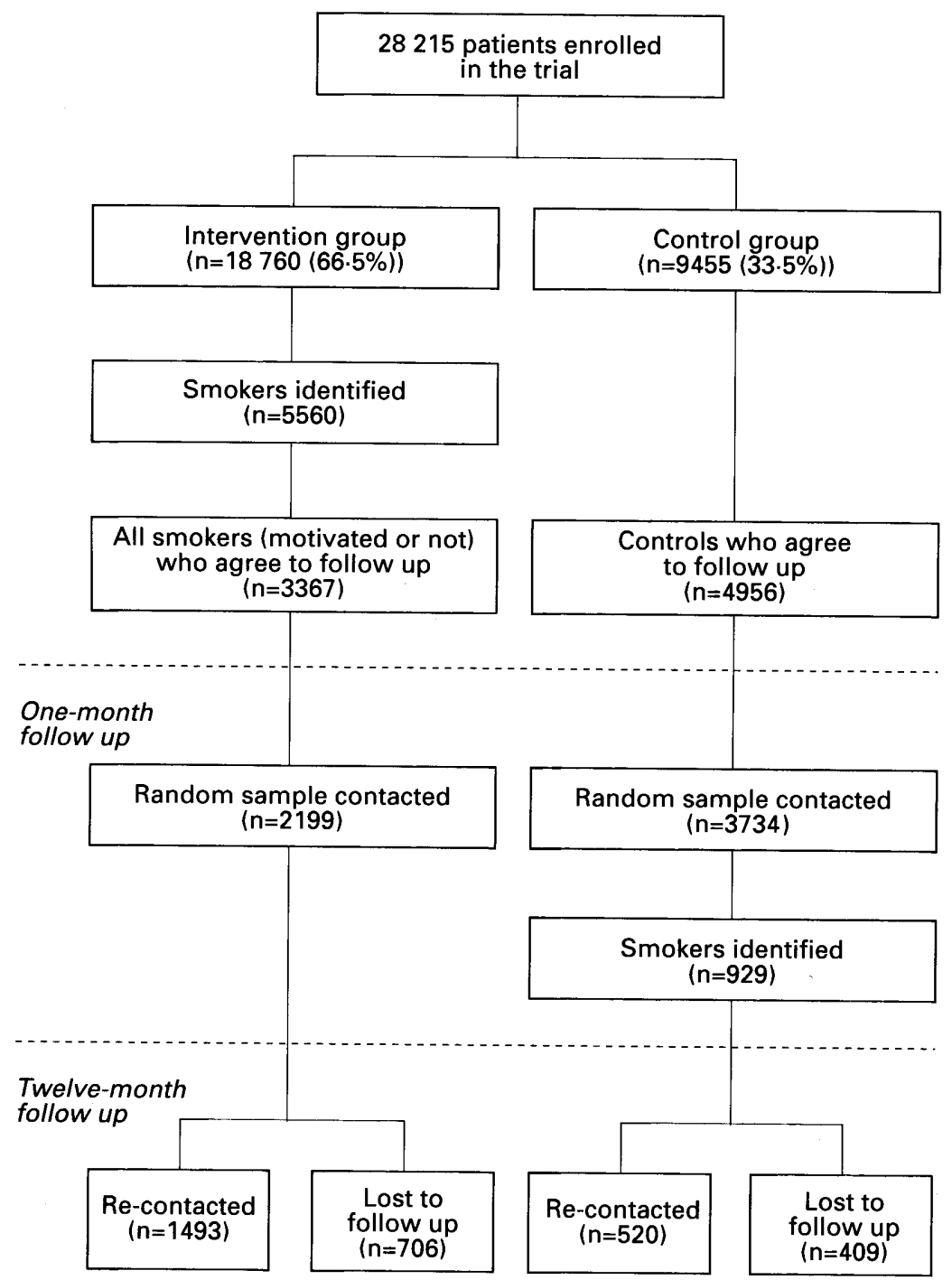

Recruitment and follow-up procedures and frequencies. indicate that large numbers of doctors may either be unwilling to participate or provide poor compliance with intervention protocols, with rates of participation varying between $2.7 \%$ and up to $59 \%$ depending on the sample size and methods of recruitment used. ${ }^{12}$ Our large sample therefore corresponds favourably with most known GP intervention participation rates.

\section{SUBJECTS}

According to patient information sheets received, 28215 patients were enrolled in the trial over the four-week period: 18760 patients in the intervention condition, and 9455 in the control condition. Among the experimental patients, $29.6 \%(\mathrm{n}=5560)$ were self-reported smokers. A total of 3367 smokers $(60.6 \%)$ consented to follow up in the experimental group, showing a rate significantly better than the $52.4 \%$ consent rate of all patients in the control condition. $\left(\chi^{2}=93.8, \mathrm{df}=1, \mathrm{p}<\right.$ 0.05). Based on completed patient sheets, $58 \%$ of smokers in the experimental group received the cessation guide, including $78 \%$ of contacted consenters and $37 \%$ of non-consenters.

\section{PROCEDURES}

Based on the weekly envelope returns, the $\mathbf{3 7 2}$ participating doctors averaged 3.3 weeks of participation (range 1-4), enrolling an average of 22.9 patients per week (range 1-87.3). For the intervention group, the final sample of smokers represents $39.6 \%$ of all smokers receiving the intervention; for the control group, the people contacted make up $39.5 \%$ of the total number of people enrolled. The numbers involved in the recruitment procedure are presented in the figure.

\section{SUBJECT CHARACTERISTICS}

Table 1 presents subject characteristics based on the information provided at the one-month follow up. The control and intervention groups are comparable regarding age, educational level, current employment status, profession, and age starting smoking. Significant differences were found, however, in sex (a greater percentage of women were in the control group), family situation (a greater percentage of single adults, alone or with children, in the control group), number of cigarettes smoked (higher average among intervention group smokers), and past attempts at cessation (more smokers in the intervention group had previously attempted to stop). These differences do not predict treatment outcomes, as shown below. The recruitment procedure, however, played a role in introducing differences between the groups. Of the 2193 experimental subjects who declined consent for follow up, $1380(63 \%)$ had declared that they did not want to stop smoking. The mean age $(\mathrm{SD})$ of a random sample $(\mathbf{n}=700)$ of non-consenters, 41.1 years (SD 15.6), is similar to that of consenters, 40.6 years (SD 14.7), but there is a striking imbalance in 
Table 1 Control and intervention group characteristics

\begin{tabular}{|c|c|c|c|c|c|c|}
\hline$x$ & & $\begin{array}{l}\text { Control } \\
(n=929)\end{array}$ & $\begin{array}{l}\text { Intervention }{ }^{\star} \\
\quad(n=2199)\end{array}$ & $\begin{array}{l}\text { Statistical } \\
\text { test result }\end{array}$ & $d f$ & p Value \\
\hline \multirow{2}{*}{$=$} & $\begin{array}{l}\text { Sex }(n=3123) \\
\text { Male }\end{array}$ & $415(44.7)$ & $1091(49.7)$ & \multirow[t]{2}{*}{$\chi^{2}=6.489$} & \multirow[t]{2}{*}{1} & \multirow[t]{2}{*}{0.011} \\
\hline & Female & $513(55.3)$ & $1104(50.3)$ & & & \\
\hline \multirow{2}{*}{+} & Mean age (years) $(n=3128$ & 40.7 (SD 14.9) & $40.6(\mathrm{SD} 14.7)$ & \multirow{6}{*}{$\begin{aligned} F & =0.01 \\
\chi^{2} & =3.976\end{aligned}$} & 1 & \multirow{6}{*}{$\begin{array}{l}0.921 \\
0.553\end{array}$} \\
\hline & $\begin{array}{l}\text { Level of highest educational diploma } \\
\text { (equivalent years of education) }(n=2938)\end{array}$ & & & & \multirow[t]{5}{*}{5} & \\
\hline$s$ & $\begin{array}{l}\text { Brevet }(9) \\
\text { Brevet technique }(9+\text { tech })\end{array}$ & $153(17.8)$ & $431(20.8)$ & & & \\
\hline \multirow[t]{2}{*}{5} & $\begin{array}{l}\text { Brevet technique }(9+\text { tech }) \\
\text { Baccalaureat }(12)\end{array}$ & $196(22.8)$ & $448(21.6)$ & & & \\
\hline & Bac. $+2(14)$ & $\begin{array}{r}173(20.1) \\
70(08.1)\end{array}$ & $\begin{array}{l}399(19.2) \\
156(07.5)\end{array}$ & & & \\
\hline \multirow{2}{*}{$\div$} & Études sup. $(>14)$ & $92(10.7)$ & $208(10.0)$ & & & \\
\hline & $\begin{array}{l}\text { Employment }(\mathrm{n}=3119) \\
\text { Employed }\end{array}$ & & & \multirow{2}{*}{$\chi^{2}=3.489$} & \multirow[t]{2}{*}{1} & \multirow[t]{2}{*}{0.062} \\
\hline \multirow[t]{2}{*}{5} & Not employed & $\begin{array}{l}600(64.7) \\
327(35.3)\end{array}$ & $1341(61.2)$ & & & \\
\hline & Profession $(n=3084)$ & $327(35.3)$ & $0851(38.8)$ & \multirow[t]{5}{*}{$\chi^{2}=7.568$} & \multirow[t]{5}{*}{5} & \multirow{5}{*}{0.182} \\
\hline$\infty$ & Management/lib. prof & $\begin{array}{r}58(06.4) \\
101(11.2)\end{array}$ & $\begin{array}{l}171(07.9) \\
229(10.5)\end{array}$ & & & \\
\hline \multirow{4}{*}{$\begin{array}{l}5 \\
-\quad 4\end{array}$} & Middle management & $180(19.9)$ & $\begin{array}{l}229(10.5) \\
425(19.5)\end{array}$ & & & \\
\hline & Employee & $263(29.1)$ & $572(26.3)$ & & & \\
\hline & Skilled/unskilled worker & $284(31.4)$ & $751(34.5)$ & & & \\
\hline & Family situation $(\mathrm{n}=3127)$ & & & \multirow[t]{5}{*}{$\chi^{2}=11.207$} & \multirow[t]{5}{*}{4} & \multirow[t]{5}{*}{0.024} \\
\hline \multirow{3}{*}{ 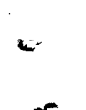 } & $\begin{array}{l}\text { Couple with children } \\
\text { Couple without children }\end{array}$ & $458(49.4)$ & $1060(48.2)$ & & & \\
\hline & $\begin{array}{l}\text { Couple without children } \\
\text { Only adult with children }\end{array}$ & $194(20.9)$ & $547(24.9)$ & & & \\
\hline & $\begin{array}{l}\text { Only adult with children } \\
\text { Only adult, no children }\end{array}$ & $\begin{array}{r}80(08.6) \\
118(12.7)\end{array}$ & $140(06.4)$ & & & \\
\hline \multirow[t]{3}{*}{ 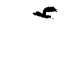 } & Other/with parents & $78(08.4)$ & $206(09.4)$ & & & \\
\hline & Mean age starting smoking $(\mathrm{n}=3124)$ & $18.9(\mathrm{SD} 6.0)$ & $18.5(\mathrm{SD} 6.0)$ & \multirow{6}{*}{$\begin{array}{c}F=2.17 \\
F=28.082 \\
F=2.54 \\
F=0.325 \\
\chi^{2}=4.474\end{array}$} & \multirow{6}{*}{$\begin{array}{l}1 \\
1 \\
1 \\
1 \\
1\end{array}$} & \multirow{6}{*}{$\begin{array}{r}0.141 \\
<0.001 \\
0.110 \\
0.569 \\
0.034\end{array}$} \\
\hline & Mean cigarettes/day $(n=3069)$ & $15.5(\mathrm{SD} 10.6)$ & 17.8 (SD 11.0) & & & \\
\hline$\infty$ & Mean cigars/day $(n=24)$ & $4.6(\mathrm{SD} 4.1)$ & $10.6(\mathrm{SD} 9.8)$ & & & \\
\hline & Mean pipes/day $(n=40)$ & $6.1(\mathrm{SD} 4.0)$ & $7.3(\mathrm{SD} 7.2)$ & & & \\
\hline $2<$ & Past attempts at cessation $(\mathrm{n}=3128)$ & & & & & \\
\hline 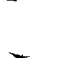 & $\begin{array}{l}\text { Yes } \\
\text { No }\end{array}$ & $\begin{array}{l}615(66.2) \\
314(33.8)\end{array}$ & $\begin{array}{r}1540(70.0) \\
659(30.0)\end{array}$ & & & \\
\hline
\end{tabular}

* Frequency $(\%)$ or mean $(\mathrm{SD})$.

Table 2 Smoking cessation results of a minimal intervention compared to control

\begin{tabular}{|c|c|c|c|c|c|}
\hline & $\begin{array}{l}\text { Control } \\
(n=929)\end{array}$ & $\begin{array}{l}\text { Intervention } \\
\quad(n=2199)\end{array}$ & $\begin{array}{l}\text { Statistical } \\
\text { test result }\end{array}$ & $d f$ & p Value \\
\hline \multicolumn{6}{|l|}{ Point prevalence } \\
\hline $\begin{array}{l}\text { Cessation at } 1 \text { month } \\
\text { Cessation at } 12 \text { months }\end{array}$ & $\begin{array}{l}38(4.1) \\
71(7.6)\end{array}$ & $\begin{array}{l}149(6.8) \\
216(9.8)\end{array}$ & $\begin{array}{l}\chi^{2}=8.379 \\
\chi^{2}=3.725\end{array}$ & $\begin{array}{l}1 \\
1\end{array}$ & $\begin{array}{l}0.004 \\
0.054\end{array}$ \\
\hline $\begin{array}{l}\text { Sustained cessation } \\
\text { Non-smokers at } 1 \text { month/non-smokers at } 12 \text { months with no relapse } \\
\text { Self-reported abstinence of one year }\end{array}$ & $\begin{array}{r}5(0.5) \\
11(1.2)\end{array}$ & $\begin{array}{l}42(1.9) \\
61(2.8)\end{array}$ & $\begin{array}{l}\chi^{2}=8.304 \\
\chi^{2}=7.845\end{array}$ & $\begin{array}{l}1 \\
2\end{array}$ & $\begin{array}{l}0.004 \\
0.020\end{array}$ \\
\hline
\end{tabular}

$\star$ Frequency $(\%)$.

Table 3 Variables correlated with smoking status of sample at 12-month follow up ${ }^{\star}$

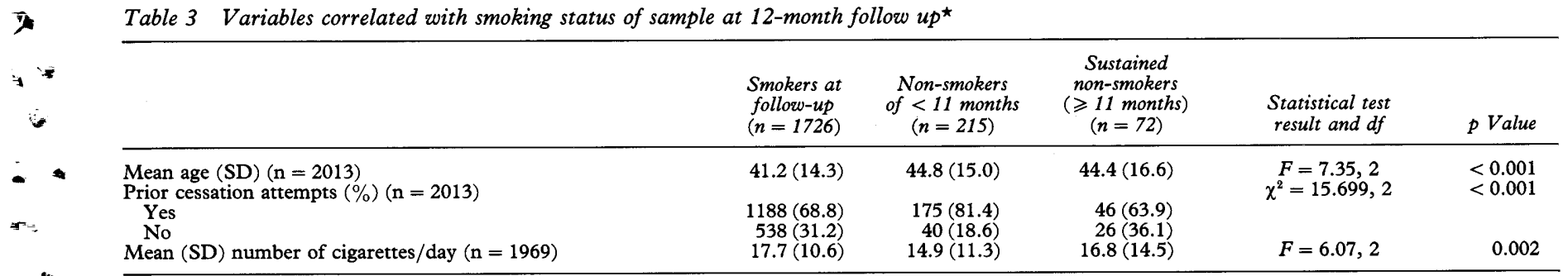

* Variables compared with smoking status: one-month follow-up measures of sex, age, level of education, employment, profession family situation, age starting smoking, current or previous cigarette consumption, prior cessation, difficulty in stopping, motive for stopping, and one-year follow-up measures of motive for stopping, current or previous cigarette consumption, education, employment, profession, and family situation.

1. 5

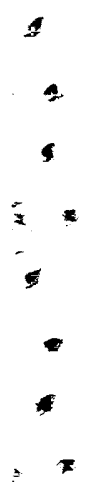

gender, with the non-consenters including $59 \%$ men and $41 \%$ women, compared with equal proportions of men and women in the measured group. Of the entire sample of controls, 4499 patients $(47.6 \%)$ declined further contact. A random sample $(n=507)$ of controls whose smoking status was undetermined, showed a mean age of 47.9 years (SD 18.4). The proportions in this group of $55 \%$ women and $45 \%$ men are quite similar to the proportions of men and women smokers in the control group who consented to follow up. The differences in characteristics measured among consenters in the control and experimental groups will be more thoroughly examined in the discussion section.

\section{FOLLOW UP}

Twelve months after the consultation, subjects interviewed at one-month follow up were again contacted by telephone and asked about their smoking status. Several attempts were made to trace subjects no longer available at the original telephone number. In the end, contact was made with 2013 subjects, $64.4 \%$ of the onemonth sample. All subjects lost to follow up are considered to be continuing smokers in cessation outcome analyses. 
ONE-MONTH SMOKING STATUS

Among the smokers in the control condition, 38 out of 929 had stopped smoking in the month following their visit to the doctor, for a cessation rate of $4.1 \%$. In the same period, 149 out of 2199 smokers in the intervention condition had stopped smoking, for a cessation rate of $6.8 \%$ (difference $=2.7$ percentage points, $95 \% \mathrm{CI}=1.05$ to 4.35$)$. This difference is significant $\left(\chi^{2}=8.379, \mathrm{df}=1\right.$, $\mathrm{p}<0.005)$, as shown in Table 2 .

\section{SMOKING STATUS AT 12 MONTHS}

Table 2 indicates sustained cessation measured in two ways. The most conservative outcome result counted as sustained non-smokers only those who were non-smokers at one month, reported sustained abstinence, and were nonsmokers at 12 months. A significant difference was found between intervention $(1.9 \%)$ and control groups $(0.5 \%)$ (difference $=1.4$ percentage points, $95 \% \mathrm{CI}=0.67$ to $2.13 ; \chi^{2}=$ 8.304, df $=1, \mathrm{p}<0.005$ ).

A second measure, counting all reported sustained abstinence of 12 months or more, is also significantly better in the intervention group $(2.8 \%)$ than in the control group $(1.2 \%)$ (difference $=1.6$ percentage points, $95 \% \mathrm{CI}$ $=0.62$ to $2.58 ; \chi^{2}=7.845, \mathrm{df}=2, \mathrm{p}<0.05$ ). A small number of smokers in both groups, control $(n=7)$ and intervention $(n=11)$, had stopped smoking at the time of the one-month follow up, relapsed, and then stopped smoking again, and were non-smokers at the time of the one-year follow up. These smokers are not counted as sustained abstainers, as none reported sustained abstinence of more than 11 months.

Point prevalence measured at the 12-month follow up showed that $9.8 \%$ of intervention patients were not smoking at the one-year follow up, compared with $7.6 \%$ of the control group (difference $=2.2$ percentage points, $95 \% \mathrm{CI}=0.09$ to 4.31 ). The difference in point prevalence at 12 months is marginally significant $\left(\chi^{2}=3.725, \mathrm{df}=1, \mathrm{p}=0.054\right)$.

\section{FACTORS IN CESSATION}

$\chi^{2}$ Analyses and analyses of variance were done to discover the factors that were significantly different between current smokers, recent nonsmokers, and self-reported sustained nonsmokers. Because of the large number of variables investigated, statistical significance is judged at $0.05 / 15$ (the probability level for one test) $/$ (the number of variables investigated) $=$ 0.003 . Only those variables with $\mathrm{p}<0.003$ were considered to be correlated to the outcome. These results are presented in Table 3 .

The mean age of current smokers is significantly lower than that of non-smokers. This corresponds to a general finding that cessation occurs more frequently in older age groups. ${ }^{11}$ Age differences by 10-year age brackets (15-24, 25-34, 35-44, 45-54, 55-64, 65 or more) compared with a combination variable of smoking status and experimental group (six categories $)$ are not significant $\left(\chi^{2}=32.742 \mathrm{df}\right.$ $=25 \mathrm{p}=0.138$ ).

Two smoking behaviour variables also differed according to smoking status. Past quitting behaviour was similar among longterm non-smokers and current smokers, but recent non-smokers were more likely to have already attempted cessation previously. More than a third $(37.7 \%)$ of the sustained nonsmokers from the intervention group had never before stopped smoking, compared with $27.3 \%$ for the control group $\left(\chi^{2}=17.078, \mathrm{df}\right.$ $=5, \mathrm{p}=0.004$ ).

The last variable to show a significant relationship with smoking status is reported daily cigarette consumption at 12-month follow up. Differences appear between all three groups, but most emphatically between the higher daily rates for smokers (17.7 cigarettes/day) and sustained non-smokers (16.8 cigarettes/day) and the lower rate of recent non-smokers (14.9 cigarettes/day). Putting smokers into smoking categories of light (1-10 cigarettes/day), moderate (11-20 cigarettes/day) and heavy (21 or more cigarettes/day), we find that, comparing the combination variable of experimental group and smoking status (six categories), there are more previously heavy smokers among quitters in the intervention group than in the control group: $30.1 \% v 23.9 \%$; and fewer previously light smokers : $36.1 \%$ v $49.3 \%\left(\chi^{2}=36.179\right.$ $\mathrm{df}=10 \mathrm{p}<0.001$ ).

\section{Discussion}

This study evaluates what happens to an entire population of smokers, those who say they want to quit and those who say they do not want to quit, when they are questioned about their smoking, compared with those who are not so questioned. The minimal intervention was defined as the asking of two questions. The contents of a brochure, however, were not considered to be an element of the intervention; it appears that the effect of minimal pamphlets is as good as state-of-the-art brochures. ${ }^{13}$

Results from self-help methods may come from the cognitive commitment or declaration of intention to stop that accompanies a request for material, and not from what is done with the material afterwards. Only sufficiently motivated quitters use self-help materials; what is important is motivating smokers to make the attempt to quit. ${ }^{14}$ If a patient has just stated that he or she wants to stop, the doctor must have some response available, and we propose that providing any reputable health promotion brochure discussing smoking cessation could be used as a minimum response.

\section{DIFFERENCES IN INTERVENTION AND CONTROI} GROUPS

Major issues remain in the interpretation of this study's results. The nature of the study, which attempted to keep the aspects of evaluation to a minimum at the time of the intervention, has resulted in potential prob- 
lems in comparability between the control and intervention groups.

\section{INDUCED BIAS}

This study attempted to investigate the basic effect of systematically talking about smoking, and it was necessary for measurement purposes to have a control group in which the topic of smoking was not introduced by the GP. For this reason, the establishment of our two groups took place in a one-month interval, a source of possible bias. A second necessity for this study was the need to ask the patients for permission to contact them outside the consultation. This is not a requirement that may be found in other societies, but in France, the right to privacy is written into the law in terms of experimentation.

It was also felt that doctors would be unwilling to proceed with an invasive technique, such as a follow up on behalf of the doctor. Therefore, a strong potential for bias in the composition of the groups could have been introduced with the smokers in the experimental group being more likely to agree to further contact if they also had indicated their desire to stop smoking, whereas the same might not be true of the control group who had not been questioned about their smoking.

In the experimental group, 1380 smokers indicated that they did not want to stop smoking and declined consent for further contact. If we count them all as continuing smokers and include them in the analysis, the one-month cessation rate for the experimental group $(\mathrm{n}=3579)$ is the same $(4.2 \%)$ as is found in the control group (4.1\%). In longterm cessation, however, there is significantly less relapse in the experimental group (72\%) than in the control group $(87 \%)\left(\chi^{2}=3.63\right.$, $\mathrm{p}<0.05$, one-tailed, $\mathrm{p}<0.10$ two-tailed), and the overall cessation rate would still be double that for controls $\left(1.2 \% v 0.5 \%, \chi^{2}=5.92\right.$, $\mathrm{p}<0.05$, difference $=0.7$ percentage points, $95 \% \mathrm{CI}=0.12$ to 1.28 ). In addition, we feel that this potential source of bias is not as strong as it first appears to be.

Within the doctor-patient relationship, because of a desire to please the doctor, it is possible that a greater percentage of smokers would say that they want to stop smoking, or feel less resistance to refuse the interview, or both. As is discussed below, we feel that smokers of all levels of readiness to stop were more likely to agree to follow up in the experimental group than in the control group.

The rates of consent to be surveyed by the regional health observatory were significantly different between the two groups, with a larger proportion of the smokers in the experimental group agreeing to contact $(60.6 \%)$ than of the entire control group (52.4\%), among which the smokers had not yet been identified. As the topic of the proposed survey was "health", no direct bias can be assumed, only a more pronounced wariness on the part of the controls, as opposed to the intervention smokers who, for the most part, probably made a connection between the survey and the questions about their smoking. Perhaps doctors were more reticent with controls, and did not press them to provide their telephone numbers.

\section{SMOKING PREVALENCE}

The intervention and control group differences in the percentage of women may be related to the different reported prevalence of smoking between groups. Whereas $29.6 \%$ of patients in the intervention group identified themselves as smokers to their doctors, only $24.9 \%(\mathbf{n}=$ $929 / 3734$ ) of the control patients interviewed reported themselves to be smokers (or exsmokers for no longer than one month) at the one-month follow up. This difference is significant $\left(\chi^{2}=34.19, \mathrm{df}=1, \mathrm{p}<0.05\right)$. In 1991, there were more men smokers than women smokers in France ( $44 \% v 36 \%),{ }^{15,16}$ so if the consenting control patients have a greater proportion of women, the overall percentage of smokers would drop. In addition, non-consenters in the control group may have included a larger proportion of sr.zokers.

\section{GROUP CHARACTERISTICS}

The other differences between the groups reflect the different proportions of men and women. The family situation of more single adults in the control group may be an artefact of the larger proportion of women in the control group. Among men, $13.2 \%$ were single, among women, $23.8 \%\left(\chi^{2}=126.636\right.$, $\mathrm{df}=4, \mathrm{p}<0.001)$.

Another difference in the composition of the intervention and control groups is in number of cigarettes smoked per day. This may also be an artefact of lighter smoking among women in the control group. Women smoked an average (SD) of 15.5 (SD 9.7) cigarettes per day compared with 18.9 (SD 11.9) for men ( $F=$ 75.39 , df $=1, \mathrm{p}<0.001)$. Finally, prior cessation attempts are also lower among women. Among men, $72 \%$ had previously attempted cessation; among women, $66 \%\left(\chi^{2}=13.36\right.$, df $=1, \mathrm{p}<0.001)$ had tried.

Differences between control and intervention baseline measures are important only if they are sufficient to influence outcome. ${ }^{17}$ As sex was not correlated with smoking status outcome $\left(\chi^{2}=2.774\right.$, df $\left.=2, p=0.250\right)$, we suggest that the groups can be considered comparable in showing that even minimal action provided routinely is better than usual care.

\section{DIFFERENCES IN DECEPTION RATES}

In some circumstances, a proportion of smokers do not admit to their actual smoking status. This proportion is generally estimated at around $25 \%$ in trials, but can be highly variable among populations. ${ }^{18}$ Invasive biochemical validation techniques appear to be increasingly less acceptable in smoking trials verification, ${ }^{19}$ and the difficulty in organising a large random sample of quitters discouraged 
our use of such a technique. Deception rates in a comparative trial are important, however, if there may be differences between the groups.

In this trial, if there is a difference in deception rates, the difference in smoking rates may indicate that smokers are more apt to hide their smoking from unknown interviewers than from their GP. If this is so, it stimulates an intriguing question: do GPs have access to smokers who would not define themselves as such in surveys? If, in this general practice population, different rates of truthful selfreport are in operation, with more deception among the controls, the initial cessation rate would in likelihood be even smaller than the rather high $4.1 \%$ found for them in this trial.

\section{RANDOMISATION BIAS}

We believe that the doctors did not induce bias in randomisation. The patient randomisation sheets were gummed together at the top to encourage maintaining the randomisation schedule of two intervention group patients to one control. Thus, if each patient sheet was used in turn, the ratio of intervention patient sheets to control patient sheets received should be $2: 1$. We cannot verify that doctors did not systematically deviate from the randomisation procedure, either by not enrolling patients if the "wrong" condition was indicated, or by skipping sheets. If this happened, however, it would be time-consuming to maintain the correct proportion. But $90 \%$ of the doctors sent back patient randomisation sheets in the proportion of $2: 1$, and the number of patient sheets $(n=1729)$ provided by the remaining $10 \%$ of doctors is only $6 \%$ of the total number of patients seen. Therefore it seems unlikely that systematic bias was introduced in this way.

\section{Conclusion}

It is important to demonstrate that very minimal anti-smoking intervention can be shown to have a statistically significant impact on smoking cessation rates if done on a large enough scale. In this trial, the intervention, which consisted only of asking about smoking status and providing a brochure to interested smokers, produced additional cessation in the following month of $2.7 \%$ over natural cessation rates, an increase of $60 \%$. This significant difference was maintained despite relapse in both groups, producing four times the rate of sustained cessation in the intervention group.

Three variables that are often related to successful cessation-older age, prior cessation, and lighter smoking ${ }^{20}$ - vary significantly between current smokers, short-term quitters and long-term ex-smokers in the intervention group of this study. Generally, successful cessation is a result of more than one cessation attempt. ${ }^{21}$ Although most of successful long-term abstainers in this trial were likely to have already tried to stop, $38 \%$ of those receiving the intervention had never before attempted cessation. This is signifi- cantly higher than the rate observed among quitters in the control group. Lighter smokers, also, are more likely to stop in natural cessation, ${ }^{20}$ but the effect of the intervention group modified this predictor: heavy smokers in the intervention group were more likely to stop than those in the control group. Younger people in the experimental group were just as likely to stop as older people.

The results concerning these three variables indicate that cessation in the intervention group may have been more likely to occur among people who are generally considered to be less likely to spontaneously stop smoking and to remain abstinent.

This trial suggests that simply identifying smokers and providing cessation materials to smokers who want to stop may significantly increase long-term sustained cessation rates. This information is important for general practitioners who have been reticent to become involved in smoking control, because such a step is not time consuming, judgmental, or invasive. This study suggests the potential effectiveness of the first step in a process that has several steps to go.

In France, where about a third of the general practitioners are themselves smokers, ${ }^{22,23}$ and where currently only $37 \%$ of GPs report counselling patients to stop smoking in cases where patients do not have smoking-related illness and do not initiate the topic, ${ }^{22}$ it may be particularly useful for doctors to know that minimal intervention can be a legitimate response to smoking. If, among the two-thirds of all smokers in France seen by GPs in one year, only $2 \%$ stop smoking permanently, that would be the equivalent of 200000 people, clearly a result of great clinical significance.

In addition, numerous studies indicate that anti-tobacco messages arriving routinely over time have a cumulative effect, ${ }^{10,13,24}$ and the effect of instigating a routine anti-tobacco procedure that is known to help some smokers might lead to considering more intensive efforts routinely.

The short-term results of this trial suggest that just asking about smoking may increase cessation among general practice patients. In the long-term, $72 \%$ of smokers in the intervention group who were not smoking at one month relapsed, compared with $87 \%$ of controls, which explains the greater difference in rates of sustained abstinence.

Once smokers have tried to stop, they are likely to try again. ${ }^{21}$ Therefore increasing the initial cessation rate is useful even if relapse rates are high. In addition, as Russell et al analysed in their path-breaking study of the effectiveness of GP advice on consecutive patients, smoking cessation may be significantly higher following an intervention for up to four months. ${ }^{8}$ The results of the present trial indicate that the doctor may increase the rate of long-term sustained cessation up to fourfold simply by asking: "Are you a smoker?" and "Do you want to stop?", and then providing a brochure to interested smokers. Clearly, this is an important message for general practitioners. 
Financial support from the French Ministry of Health, EEC Europe Against Cancer Programme and the French Committee for Health Education is gratefully acknowledged. We would like to thank the staff and officials of the UREMEC and the ORS of Marseille for their invaluable support in undertaking this trial. We would also like to thank all of the coordinators and participating general practitioners in the PACA region.

1 Reid DJ, Killoran AJ, McNeill AD, Chambers JS. Choosing the more effective health promotion options for reducing a nation's smoking prevalence. Tobacco Control reducing a nation's

2 Dickinson JA, Wiggers J, Leeder SR, Sanson-Fisher RW. General practitioners' detection of patients' smoking General practitioners detection of patients' smoking

status. Med $\mathcal{f}$ Aust 1989; $150: 420-6$.
Anda RF, Remington PL, Sienko DG, Davis RM. Are Anda RF, Remington PL, Sienko DG, Davis RM. Are
physicians advising smokers to quit? The patient's perspective. $¥ A M A$ 1987; $257: 1916-19$.

4 Frank E, Winkleby MA, Altman DG, Rockhill B, Fortmann SP. Predictors of physicians' smoking cessation advice. fAMA 1991; 266: 3139-44.

5 Fowler G. Educating doctors in smoking cessation. Tobacco Control 1993; 2: 5-6.

6 Glynn TJ, Manley MW, Pechacek TF. Physician-initiated smoking cessation program: The National Cancer Institute Trials. In Engstrom $\mathrm{P}$ et al, eds. Advances in cancer control. New York: Alan R Liss, 1990.

7 Jamrozik K, Vessey M, Fowler G, Wald N, Parker G, Van Vunakis $H$. Controlled trial of three different antismoking
interventions in general practice. $B M \mathcal{F} 1984 ; 288$ : intervention

5

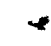

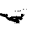

8 Russell MAH, Wilson C, Taylor C, Baker CD. Effect of general practitioners' advice against smoking. $B M \mathfrak{F} 1979$ 2: 231-5.

9 Bronson DL, Flynn BS, Solomon LJ, Vacek P, SeckerWalder RH. Smoking cessation counseling during periodic health examinations. Arch Intern Med 1989; 149 . 1653-6.

10 Slama K, Redman S, Perkins J, Reid ALA, Sanson-Fisher RW. The effectiveness of two smoking cessation programmes for use in general practice: a randomised clinical trial. $B M \mathcal{F} 1990 ; 300: 1707-9$.

11 Kottke TE, Battista RN, DeFriese GH, Brekke ML. Attributes of successful smoking interventions in medical practice: a meta-analysis of 39 controlled trials. $\mathcal{F} A M A$ 1988; 259: 2883-9.

12 Kottke TE, Brekke ML, Solberg LI, Hughes JR. A randomized trial to increase smoking intervention by physicians. Doctors Helping Smokers, Round 1. $\mathcal{F} A M A$ 1989; $261: 2101-6$.

13 Lichtenstein E, Glasgow RE. Smoking cessation: What have we learned over the past decade? $\mathcal{f}$ Consult Clin Psychol 1992; 60: 518-27.

14 Glynn TJ, Boyd GM, Gruman JC. Essential elements of self-help/minimal intervention strategies for smoking cessation. Health Educ $Q 1990 ; 17: 329-45$.

15 Baudier F, Grizeau D, Dutrech V, Dressen C, Danzon M. Les Français et le tabac en 1992. Consommation et opinions avant l'entrée en vigueur des décrets sur l'interdiction de fumeur. Santé Publique 1992; 4: 33-41.

16 Bosanquet N, Trigg A. A smoke-free Europe in the year 2000: wishful thinking or realistic strategy? Health Policy Unit discussion paper 4. Chichester: Carden Publication, 1991.

17 Altman DG, Doré CJ. Randomisation and baseline comparisons in clinical trials. Lancet 1990; 335: 149-53.

18 Weissfeld JL, Holloway JJ, Kirscht JP. Effects of deceptive self-reports of quitting on the results of treatment trials for smoking: A quantitative assessment. $\mathcal{f}$ Clin Epidemiol $1989 ; 42: 231-343$.

19 Hollis JF, Lichtenstein E, Vogt TM, Stevens VJ, Biglan A. Nurse-assisted counseling for smokers in primary care. Ann Intern Med 1993; 118: 521-5.

20 McWhorter WP, Boyd GM, Mattson ME. Predictors of quitting smoking: The NHANES I follow-up experience. f Clin Epidemiol 1990; 43: 1399-405.

21 Prochaska JO, DiClemente CC. Transtheoretical therapy: Towards a more integrative model of change. Psychother Theory Res Pract 1982; 19: 276-88.

22 Tessier J-F, René L, Neijari C, Belougne D, Moulin J, Fréour P. Attitudes and opinions of French general practitioners towards tobacco. Tobacco Control 1993; 2: 226-30.

23 Trédaniel J, Karsenty S, Chastang C, Slama K, Hirsch A. Les habitudes tabagiques des médecins généralistes français. Rev Mal Resp 1993; 10: 35-8.

24 Ockene JK, Lindsay EL, Berger L, Hymovitz N. Health care providers as key change agents in the community care provion trial for smoking cessation (COMMIT). Int Quart Commun Health Educ 1990/91; 11: 259-69.

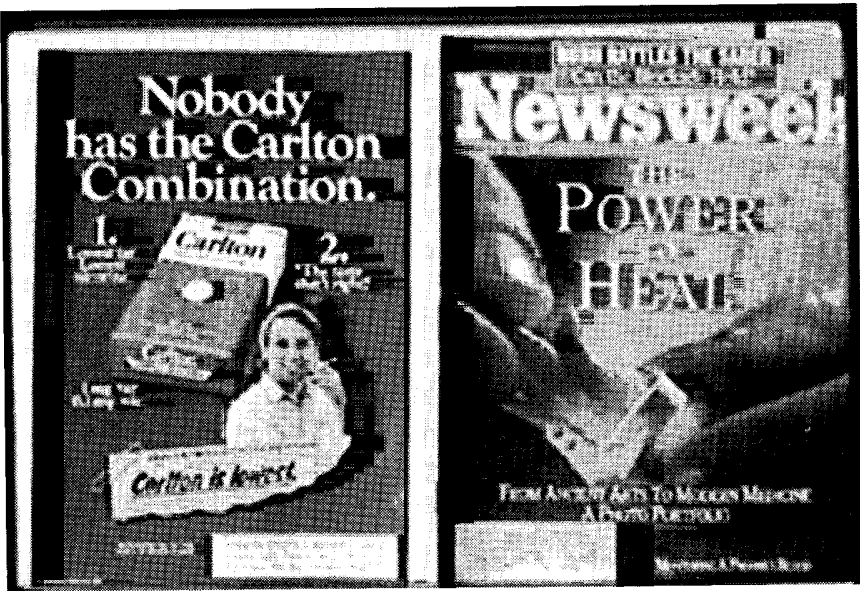

